\section{Liebig, Justus von}

\author{
A. M. Gressner ${ }^{1}$ und O. A. Gressner ${ }^{2}$ \\ ${ }^{1}$ Labor Dr. Wisplinghoff Berlin, Berlin, Deutschland \\ ${ }^{2}$ Labor Dr. Wisplinghoff Köln, Köln, Deutschland
}

Lebensdaten Deutscher Chemiker, geboren am 12. Mai 1803 in Darmstadt, gestorben am 18. April 1873 in München.

Verdienste Studium der Chemie in Bonn, Promotion 1822 an der Universität Erlangen, Assistent bei Joseph Louis GayLussac in Paris. Im Jahr 1824 Professor an der Universität Gießen, ab 1852 Professor für Chemie an der Universität München und ab 1859 bis zu seinem Tode Präsident der Bayerischen Akademie der Wissenschaften.
Liebig ist einer der bedeutendsten Chemiker des 19. Jahrhunderts, aus dessen Schule 44 Nobelpreisträger hervorgingen.

Forschungsschwerpunkte Pflanzlicher und tierischer Stoffwechsel, Agrikulturchemie, analytische Chemie und Elementaranalytik. Entdeckungen von Chloral und Chloroform und Entwicklung von Verfahren zur Herstellung von Cyaniden und Silberspiegeln. Entwicklung des Liebig-Fleischextrakts. Gründung der „Annalen der Pharmazie“ (später „Liebigs Annalen der Chemie").

\section{Literatur}

http://www.Liebig-Museum.de/Justus.html 